\title{
Evaluation of Activation Energy for Agricultural Residues with Ignition Temperature
}

\author{
Jeng-Liang Lin ${ }^{*}$ \\ Department of Biomechatronic Engineering, National Chiayi University, Chiayi, Taiwan \\ Received 11 November 2021; received in revised form 15 January 2022; accepted 16 January 2022 \\ DOI: https://doi.org/10.46604/ijeti.2022.8889
}

\begin{abstract}
The objective of this study is to evaluate the activation energy of agricultural residues with their ignition characteristics. The ignition temperature of agricultural residues (peanut shell, rice hull, and rice straw) is determined by measuring particle temperature, particle luminosity, and gas temperature for samples weighing 2.0, 2.5, and 3.0 grams. The maximal slope of the particle temperature versus furnace temperature is used to determine the occurrence of ignition. Values of activation energy are analyzed by the Semenov model with the measured ignition temperature. Results show that the particle ignition temperature is 317,324 , and $330^{\circ} \mathrm{C}$ for rice straw, peanut shell, and rice hull, respectively. The results also indicate that the particle ignition temperature reduces as the volatile content increases and the sample amount decreases. The value of activation energy is 157.2, 170.3, and 192.8 $\mathrm{kJ} / \mathrm{mole}$ for rice straw, peanut shell, and rice hull, respectively.
\end{abstract}

Keywords: agricultural residues, ignition, combustion, activation energy

\section{Introduction}

Agricultural residues are naturally in the form of cellulose organic solids after harvesting and processing operation. Combustion is one of the most effective methods to dispose of agricultural residues since it is rapid and clean and can provide energy to the agricultural processing industry. To utilize agricultural residues as fuel by combustion, the ignition characteristics of agricultural residues should be analyzed. There are a lot of studies on the investigation of the ignition and combustion characteristics of coal. Although the physical and chemical properties of agricultural residues are different from those of coal, the ignition characteristics of agricultural residues might be similar to that of coal since agricultural residues and coal all belong to solid carbonaceous materials [1].

The combustion process of cellulose particles, containing ignition and burnout processes, is a chemical reaction between solids and oxygen. The occurrence of ignition is dependent on the energy balance between heat generation and heat loss. In a heating condition, the particle temperature rises and eventually ignites the particles when the heat generation is more than the heat loss. If the dominant control factor of combustion is diffusion, the combustion process of fixed carbon (FC) should comply with the Nusselt square law until the carbon is burned out after the combustion process of volatiles is completed.

The ignition mechanism of cellulose particles can be heterogeneous or homogeneous. For heterogeneous ignition, the volatiles and FC react with oxygen at the same time. This is due to the fact that the released volatile flux is not sufficient enough to consume all the oxygen diffusing toward the particles [2]. Also, the particle surface temperature reaches the ignition temperature during pyrolysis. The circumambient flame will be at the surface of the particles. For homogeneous ignition, the

* Corresponding author. E-mail address: jllin@ mail.ncyu.edu.tw

Tel.: +886-5-2717656; Fax: +886-5-2717647 
released volatiles react with oxygen alone due to the enormous volatile flux forcing oxygen away from the particle surface [3]. Therefore, the flame will be driven away from the particle surface. Besides, an initial flash of light will occur for the homogeneous ignition, and then the glow of the remaining particles will indicate slower heterogeneous combustion. Generally, the surface luminosity rather than the flash of light should be detected when the ignition mechanism is heterogeneous.

The factors influencing the ignition temperature include the balance between heat generation and heat loss as well as the properties of reactants. Fuel particles cannot ignite immediately because of the time required for the following two reasons. The first reason is that the particles placed in a high-temperature environment increase their temperature by convective and radiative heat transfer. The second reason is that the concentration of radicals is sufficient to allow transition from slow oxidation to rapid combustion. The critical condition of ignition occurs when the rates of heat release and heat loss are equal, as well as the derivatives of both these rates with respect to temperature are also equal. The criterion of ignition is illustrated by Line I on Fig. 1. The gas temperature for which the $\mathrm{Q}_{1}$ line is tangent to $\mathrm{Q}_{\mathrm{g}}$ line is $\mathrm{T}_{\mathrm{gi}}$, i.e., the gas temperature at ignition. The temperature at the point of tangency is the particle ignition temperature $\mathrm{T}_{\mathrm{pi}}$. A small increase in gas temperature from this condition will result in a temperature "jump" of a burning particle shown as line III. Although there are two $\mathrm{Q}_{1}$ lines on the Q-T coordinate to be crossing and tangent to $\mathrm{Q}_{\mathrm{g}}$ line, the temperature rise does not always exist for the increase of gas temperature in the range of $\mathrm{T}_{\mathrm{g}}<\mathrm{T}_{\mathrm{gi}}$ as line II since the heat loss is more than the heat generation.

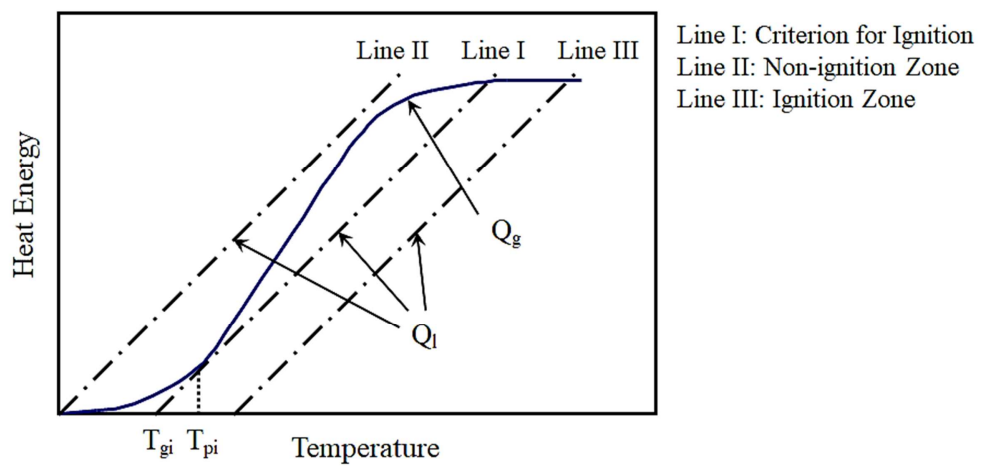

Fig. 1 Variation of heat generation $\left(\mathrm{Q}_{\mathrm{g}}\right)$ and heat loss $\left(\mathrm{Q}_{\mathrm{l}}\right)$ with temperature [4]

The ignition characteristics of peanut shells were studied and the results showed that the homogeneous ignition could occur when the furnace temperature was set above $600^{\circ} \mathrm{C}$ [5]. However, the minimum ignition temperature could be an important parameter for the production of activated carbon from agricultural residues. Therefore, this study aims to measure the minimum ignition temperature and evaluate the activation energy of agricultural residues (peanut shell, rice hull, and rice straw) after agricultural processing. The obtained ignition characteristics of agricultural residues would be useful in designing a proper processing system along with its operation parameter setting for disposal and recovery.

\section{Literature Review}

There was literature regarding biomass ignition and combustion [6-9]. Also, coal particles have been investigated extensively since coal is a widely used fossil fuel. The variation of ignition temperature with particle size, volatile content, ash content, and oxygen concentration has been investigated and interpreted [10-12]. Generally, the ignition temperature was higher for smaller particle size, lower volatile content, and lower oxygen concentration; higher ash content having higher ignition temperature could be resulted from lower combustion heat. Since the ratio of surface area to volume was higher for smaller particles, which resulted in higher heat loss, smaller particles would have higher ignition temperature. The ignition temperature could decrease $5-8^{\circ} \mathrm{C}$ per $1 \%$ of the volatile matter $(\mathrm{VM})$ increment due to the difference in reactivity. The ignition temperature was likely to decrease hyperbolically with an increase of oxygen partial pressure because higher oxygen concentration increased the reaction rate and retarded the VM to escape from the particles, which would result in the ignition temperature asymptotically approaching a final value. 
Observation of flash occurrence has been used frequently to determine the ignition characteristics of particles in a heated furnace [13-16]. However, gas analysis [17-18] and particle temperature analysis [19-20] could also be used to determine the ignition characteristics. When the ignition temperature was determined by the variation of particle surface temperature during an experiment, the variation of particle temperature could be as follows. For a particle heating in a furnace, the rise of particle temperature would become slower after heating for a while, and its temperature would rise rapidly again if ignition occurs and heat generation transfers back to the particle. Due to this heat transfer phenomenon, there should be an inflection point in the particle heating curve. Hence, the particle temperature on the inflection point could be defined as the ignition temperature, which could be determined by the point where the second derivative of particle temperature with respect to time was zero from the heating curve. However, the inflection point was not used to denote ignition because at the point of inflection the fuel particles would have ignited already [20]. Furthermore, for the particle diameter greater than 6 mm, there was no inflection point in the particle heating curve because the temperature gradient could exist inside the particles [19].

Therefore, the maximal slope of the particle temperature versus furnace temperature was introduced to analyze the ignition temperature for larger particles. The physical interpretation could be as follows. When the particles were put into a hot furnace, the particles were quickly heated, and then the heat was rapidly transferred through the particle surface. Therefore, the temperature gradient should be very large at the particle surface. Since the temperature inside the particles would increase, the temperature gradient would decrease gradually with the increase of heat transfer into the particles. At the moment of ignition occurrence, the particle surface quickly receiving heat would result in the greater temperature gradient at the particle surface and the heat transfer into the particles would increase again. As combustion proceeded and reached steady, the temperature distribution inside the particles was likely to be uniform and the temperature gradient was to be zero.

An ignition index Fz was developed and used as an index to indicate the tendency of particle ignition and combustion, as well as to evaluate the ignition characteristic of coal particles [21].

$$
F z=(M C+V M)^{2} \times F C \times 100
$$

The char particles of higher activity with larger Fz would be easier to ignite. The sum of VM and moisture content (MC) of coal particles based on proximate analysis could indicate the porosity level and/or specific area of the particles after the release of volatiles and moisture inside the particles. The ratio of carbon per unit surface area was higher for higher FC, so the heat generation released from the coal particle surface was higher, which would be advantageous for ignition. Therefore, the particles with higher volatility and FC were prone to ignite. However, the effect of MC + VM on char ignition was much stronger than that of FC. The ignition characteristics of coal were divided into the following five types: "very difficult to burn" for $\mathrm{Fz}<0.5$, "difficult to burn" for $0.5<\mathrm{Fz}<1.0$, "quasi-difficult to burn" for $1.0<\mathrm{Fz}<1.5$, "easy to burn" for $1.5<\mathrm{Fz}<2.0$, and "very easy to burn" for Fz $>2.0$.

The auto-ignition tendency of lignite was investigated by measuring the coal and furnace temperature increase rates [22]. The crossing point, where the curve of the coal temperature increase rate crossed that of the furnace temperature increase rate, was used to represent the auto-ignition tendency of one coal relative to another. Researchers found that the auto-ignition tendency decreased as the difference between VM and MC increased.

\section{Materials and Methods}

Peanut shell, rice straw, and rice hull, which are major agricultural residues in Taiwan, are used as experimental samples in this study. The MC levels of these materials are at the values after staying at room condition for a week. To prevent any pronounced change of MC during the entire experiment period, a batch of captive samples is kept in a sealed container to ensure that the MC of the samples will not vary even in the case of a significant change of ambient environment. Peanut shell and rice hull are in their size as received; however, rice straw is cut into about 3-4 cm long to stay on a mesh plate steadily. 
Since the ignition characteristics are affected by chemical properties significantly, especially VM, proximate analyses are necessary for this study. A $1-\mathrm{g}$ sample of the agricultural residues is heated at $100^{\circ} \mathrm{C}$ for $1 \mathrm{hr}$ exactly to determine the moisture of the sample. The weight loss of the sample during this period, in percentage, is an indication of the MC of the agricultural residues. Since VM consists of hydrogen-carbon compounds, the heating process can be used to remove VM from the agricultural residues. Thus, a 1-g sample is placed in a covered ceramic crucible and heated to $950^{\circ} \mathrm{C}$ for about 7 minutes to drive off VM. The loss in weight during the heating period is due to the elimination of moisture and VM. Then, VM can be determined since moisture is calculated from the previous test.

The tests for the percentage of ash in the fuel are carried out by heating the samples of agricultural residues to $720^{\circ} \mathrm{C}$ in an uncovered crucible for about $1 \mathrm{hr}$ until the weight of agricultural residues is steady. A constant weight means that there is only ash remaining in the crucible. FC is the value of $100 \%$ minus the sum of the percentages of moisture, VM, and ash. However, FC does not represent all the carbon that is in the agricultural residues. Some of the carbon might be in the form of distilled hydrocarbons during the determination of VM. In addition, some of the so-called FC might include hydrogen, nitrogen, oxygen, and sulfur. Proximate analyses are shown in Table 1, which indicate that all the agricultural residues in this study are in the category of "easy to burn" since Fz > 2.0.

Fig. 2 shows the experimental setup of this study schematically. The data acquisition system consists of a k-type thermocouple for measuring the gas temperature in the furnace, an infrared pyrometer of OPTEX for measuring the particle temperature, and a luminance meter of Minolta for measuring the intensity of the particle surface brightness. The thermocouple and infrared pyrometer are calibrated with ice water of $0^{\circ} \mathrm{C}$, and the luminance meter is calibrated in a completely dark environment. PCL-818HG interface card of ADVANTECH is used to connect those three instruments and a personal computer, and the output voltages of the three instruments are recorded into the personal computer by Genie.

The experimental procedures to investigate the ignition characteristic are as follows. First, a batch of samples, which can be observed from the viewing window, is placed in the center of a furnace with a mesh plate. Then, the data acquisition system is started to record the temperature of the furnace as well as the temperature and luminosity of the sample particles at an interval of $0.5 \mathrm{sec}$. A moment later, after the samples and the data acquisition system are ready, the furnace is turned on to heat the sample particles. The heating experiment usually lasts for about 10 minutes, and then the data acquisition system is turned off after the sample particles are burned out. Finally, residual char is taken out from the furnace and the furnace is turned off to cool down to ambient temperature for other experiments.

Table 1 Proximate analyses and Fz values of agricultural residue samples

\begin{tabular}{|c|c|c|c|c|c|c|c|c|}
\hline \multirow{2}{*}{ Sample } & \multicolumn{3}{|c|}{ Dry basis (wt\%) } & \multicolumn{5}{c|}{ Wet basis (wt\%) } \\
\cline { 2 - 10 } & VM & FC & Ash & MC & VM & FC & Ash & Fz \\
\hline Peanut shell & 79.06 & 19.74 & 1.22 & 14.25 & 67.79 & 16.93 & 1.05 & 11.39 \\
\hline Rice hull & 77.02 & 16.92 & 6.06 & 13.31 & 66.77 & 14.67 & 5.25 & 9.41 \\
\hline Rice straw & 82.30 & 10.43 & 7.27 & 17.42 & 67.96 & 8.62 & 6.00 & 6.28 \\
\hline
\end{tabular}

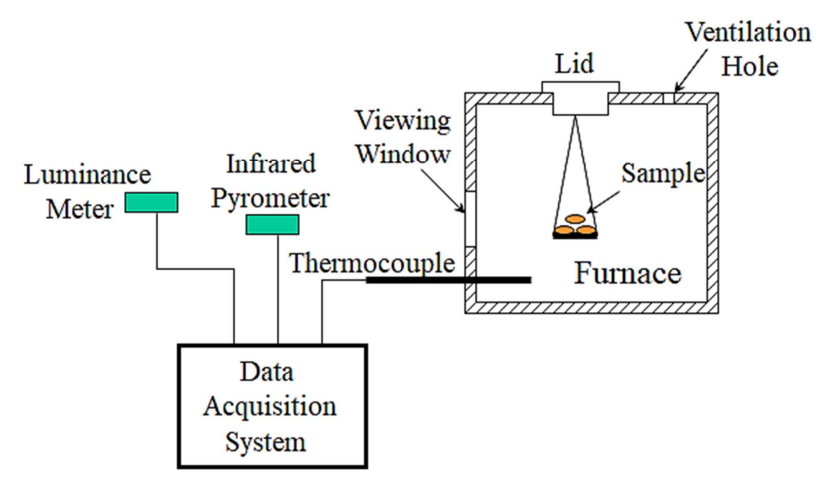

Fig. 2 Experimental setup for the measurement of ignition characteristics 
The infrared pyrometer is used to measure the particle temperature. Since the emissivity setting value is a major parameter for the reading value of the infrared pyrometer, the emissivity of 0.96 is adopted according to previous studies [4, 23]. Since the minimal measurement area of the infrared pyrometer is $\phi 32 \mathrm{~mm}$, it is inappropriate to perform the ignition experiment for a single particle. Hence, the minimal amount of sample particles in the mesh plate should be more than $\phi 32 \mathrm{~mm}$. Because the size of the mesh plate is $\phi 60 \mathrm{~mm}$ to fit the furnace viewing window properly, a batch of agricultural residues particles of 2.0, 2.5, and 3.0 grams are used to study the effect of sample amounts on ignition characteristics.

Because it usually takes several hours to cool down the furnace to ambient temperature after each experimental condition, the experiments of this study are time-consuming work. To account for the natural difference of each sample, each experimental condition is replicated five times. Therefore, a total of 45 experiments are performed to analyze the effects of agricultural residue types and sample amounts on ignition characteristics.

\section{Theory of Activation Energy Evaluation}

The agricultural residues inside a high-temperature environment increase their temperature as a result of convective and radiative heat transfer. The rate of heat generation due to chemical oxidation reactions on particle surfaces increases with an increase in temperature. Eventually, the particles can ignite at the ignition temperature, $\mathrm{T}_{\mathrm{pi}}$. The ignition temperature can be determined by Semenov analysis, which requires the heat generation rate and the heat loss rate of the sample particles to be equal and tangent to each other at the ignition point (Fig. 1). The Semenov analysis can give a simple solution for $\mathrm{T}_{\mathrm{pi}}$ if the accumulation of heat within the particle is negligible, no swelling or shrinkage of the particle occurs, and no volatiles are released from the particles prior to ignition.

The Semenov ignition condition can be expressed in form of the following equations.

$$
\begin{aligned}
& Q_{g}=Q_{l} \\
& d Q_{g} / d T_{p}=d Q_{l} / d T_{p}
\end{aligned}
$$

where $\mathrm{Q}_{\mathrm{g}}$ is assumed due to the reaction at the surface of a solid particle, and $\mathrm{Q}_{1}$ is assumed only due to the heat convection and radiation. $\mathrm{Q}_{\mathrm{g}}$ and $\mathrm{Q}_{\mathrm{l}}$ can be expressed as follows.

$$
\begin{aligned}
& Q_{g}=k_{o} p_{o}^{n} h_{c} \exp \left(-E / R T_{p}\right) \\
& Q_{l}=h\left(T_{p}-T_{g}\right)+\sigma \varepsilon\left(T_{p}^{4}-T_{g}^{4}\right)
\end{aligned}
$$

Substituting the derivatives of $\mathrm{Q}_{\mathrm{g}}$ and $\mathrm{Q}_{\mathrm{l}}$ with respect to $\mathrm{T}_{\mathrm{p}}$ into Eq. (3), the following equation can be obtained.

$$
\frac{E k_{o} p_{o}^{n} h_{c}}{R T_{p i}^{2}} \exp \left(-\frac{E}{R T_{p i}}\right)=h+4 \sigma \varepsilon T_{p i}^{3}
$$

For the sample particles in a stagnant condition similar to the experimental condition in this study, hd $/ \lambda=2$. Hence, as the substitution of heat loss term in the left-hand side of Eq. (6), the activation energy can be determined by the following equation if the particle and furnace temperatures at the ignition point are known.

$$
E=\frac{R T_{p i}^{2}\left(2 \lambda / d_{p}+4 \sigma \varepsilon T_{p i}^{3}\right)}{2 \lambda\left(T_{p i}-T_{g}\right) / d_{p}+\sigma \varepsilon\left(T_{p i}^{4}-T_{g}^{4}\right)}
$$




\section{Results and Discussion}

For the samples of 3.0-gram peanut shells, the variations of particle temperature and furnace temperature as well as particle luminosity with time during the heating process are shown in Fig. 3. At the beginning of the experiment, the particle temperature and furnace temperature are identical, which verifies the emissivity setting value as 0.96 for the experimental samples. After the furnace starts to heat, the particle temperature and furnace temperature increase due to the heat transfer from the furnace as expected. However, the increase of particle temperature is not as fast as the increase of furnace temperature during the initial stage of heating. The reason for this phenomenon might be that not all the heat transfer to sample particles is used to increase the particle temperature, rather part of the heat transfer received is used for the endothermic process of moisture evaporation and pyrolysis. The experimental results for other agricultural residues all show the same trend.

After the moisture evaporation is completed and the pyrolysis is carried on to some extent, the particle temperature eventually exceeds the furnace temperature; this result represents that parts of the released volatiles during pyrolysis and/or residual char react with oxygen, and then the reaction heat is transferred back to the sample particles. However, the ignition mechanism is not homogeneous by the experimental procedures used in this study since a flash of light is not observed and the luminosity of particle samples does not increase significantly in all experiments. In addition, by experimental observation, smoke emerges from the moment of the particle temperature being about the same as the furnace temperature. Therefore, massive pyrolysis can be defined at this point quantitatively, which can represent the decomposition tendency of one agricultural residue relative to another, similar to the cross point of the coal and furnace temperature increase rates representing the auto-ignition tendency [22]. From the massive pyrolysis point, the increase of particle temperature is faster since the released volatiles and/or char react with oxygen to generate heat until the reaction heat is equal to the heat loss, which is resulted from the particle temperature being higher than the furnace temperature after the massive pyrolysis point. When char combustion is completed, the increase rate of particle temperature levels off and the particle temperature approaches the furnace temperature again.

The flash of light is not observed, and can be verified by the analysis of the luminosity variation since all luminosity values are in the range of $1-3 \mathrm{~cd} / \mathrm{m}^{2}$. Although the particle luminosity starts to fluctuate after the massive pyrolysis point, its values are not far away from the initial stage. However, there is a noticeable fact that the sample luminosity decreases slightly before the massive pyrolysis point since the color of the particle surface becomes darker after partial pyrolysis. Therefore, the ignition mechanism of agricultural residues in this study is likely to be heterogeneous because the released volatile flux is not large enough to react with all the oxygen toward the samples at slow heating procedures, even with the oxygen toward the samples containing high volatile content. In the experimental conditions of this study, it is more likely that the char combustion at agricultural residue surface occurs earlier than the ignition of VM. Hence, the experimental conditions in this study are classified as the heterogeneous mechanism [20]. The fluctuation of the luminosity should refer to the glow of the burning sample particles at slow heterogeneous combustion of residual chars. Because there is no obvious change point in the luminosity curve, using the luminosity curve to analyze the ignition temperature is not applicable.

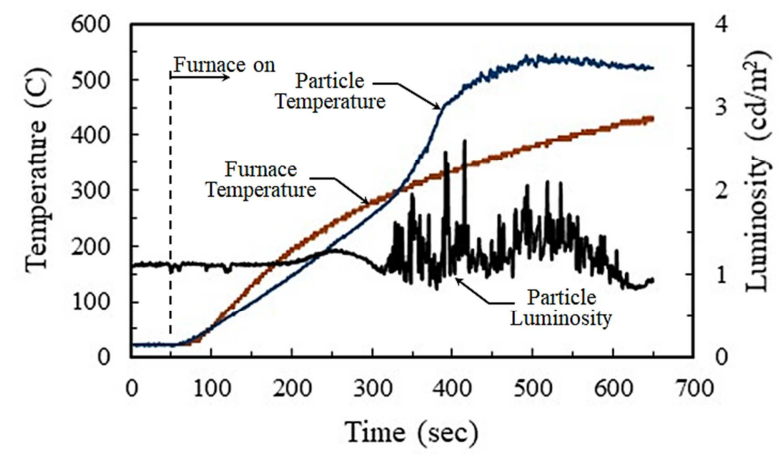

Fig. 3 Variation of particle temperature and furnace temperature as well as particle luminosity with time in a heating furnace 
It seems that there is an inflection point, which can be defined as the moment of ignition occurrence, appeared in the particle heating curve as shown in Fig. 3. The temperature on the inflection point can be determined by the point where the second derivative of particle temperature with respect to time is zero from the heating curve. However, in practice, the variation rate of particle temperature is fluctuated fiercely because of the short sampling interval and signal noise in the infrared pyrometer. Hence, it is quite difficult to directly obtain the inflection point by data processing of the sample heating curve. However, a smooth curve is obtained by plotting the particle temperature versus furnace temperature.

In Fig. 4, the variation of the slope of particle temperature versus furnace temperature with the furnace temperature is also determined, which can represent the particle temperature change for $1^{\circ} \mathrm{C}$ increment of the furnace temperature. There is a maximal slope of the particle temperature versus furnace temperature in each experiment, and then the maximal value is adopted to determine the occurrence of ignition. For a sample of 3.0-gram peanut shells, the particle temperature increases about $8^{\circ} \mathrm{C}$ with $1{ }^{\circ} \mathrm{C}$ increment of the furnace temperature at ignition occurrence. This criterion is used to determine the heterogeneous ignition characteristics in this study. In physical meaning, the maximal slope of the particle temperature versus furnace temperature indicates that a slight increase of gas temperature in the furnace can result in the sudden rise of particle temperature, which is in agreement with the interpretation in Fig. 1. Thereafter, the particle and furnace temperatures can be determined after the ignition point is obtained.

Table 2 lists the average and standard deviation of particle temperature at the massive pyrolysis point, as well as the particle and furnace temperatures at the moment of ignition occurrence for the same experimental conditions. The experimental results are very consistent with the findings in previous studies: the variation of ignition temperature is in the range of $80-85^{\circ} \mathrm{C}$ for higher volatile coal, $30-50^{\circ} \mathrm{C}$ for coal, and $60-100^{\circ} \mathrm{C}$ for char $[15,24]$. Hence, it is quite usual for agricultural residues to show the same extent of deviation since the agricultural residues of this study all belong to high volatile materials. The reason of deviation for measuring the ignition characteristics at the same experimental conditions might be that the surface reactivity and surface/volume ratio should be different naturally for each sample particle. In addition, the definition of massive pyrolysis point is justified since its values are in the range of peak weight loss rate for the burning profile of agricultural residues [25]. From the results of particle temperature at the massive pyrolysis point, the sequential tendency of decomposition from the strongest to the weakest is rice straw, peanut shell, and rice hull.

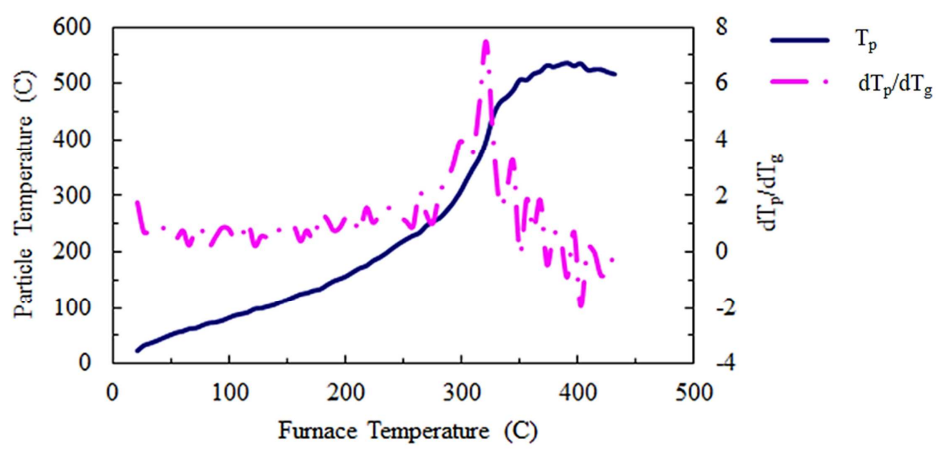

Fig. 4 Variation of the slope of particle temperature versus furnace temperature with the furnace temperature

Table 2 Experimental results for the ignition characteristics of agricultural residues

\begin{tabular}{|c|c|c|c|c|c|c|c|}
\hline \multirow{2}{*}{ Sample } & \multirow{2}{*}{ Weight $(\mathrm{g})$} & \multicolumn{2}{|c|}{ Particle temperature $\left({ }^{\circ} \mathrm{C}\right)$} & \multicolumn{2}{c|}{ Gas temperature $\left({ }^{\circ} \mathrm{C}\right)$} & \multicolumn{2}{c|}{ Massive pyrolysis point $\left({ }^{\circ} \mathrm{C}\right)$} \\
\cline { 2 - 8 } & & Average & Standard deviation & Average & Standard deviation & Average & Standard deviation \\
\hline \multirow{3}{*}{$\begin{array}{c}\text { Peanut } \\
\text { shell }\end{array}$} & 2.0 & 316.7 & 10.60 & 299.7 & 5.78 & 279.0 & 3.46 \\
\cline { 2 - 8 } & 2.5 & 321.3 & 8.2 & 302.6 & 0.6 & 287.3 & 4.6 \\
\cline { 2 - 8 } & 3.0 & 333.0 & 12.00 & 308.0 & 1.73 & 290.7 & 8.39 \\
\hline \multirow{3}{*}{$\begin{array}{c}\text { Rice } \\
\text { hull }\end{array}$} & 2.0 & 312.3 & 2.52 & 302.7 & 2.52 & 284.3 & 8.39 \\
\cline { 2 - 8 } & 2.5 & 334.3 & 9.5 & 317.8 & 6.7 & 295.4 & 9.2 \\
\cline { 2 - 8 } & 3.0 & 345.7 & 4.04 & 324.0 & 3.61 & 298.3 & 2.89 \\
\hline \multirow{3}{*}{$\begin{array}{c}\text { Rice } \\
\text { straw }\end{array}$} & 2.0 & 304.0 & 8.89 & 278.7 & 8.08 & 245.7 & 14.36 \\
\cline { 2 - 8 } & 2.5 & 322.4 & 31.9 & 297.3 & 21.4 & 269.6 & 6.6 \\
\cline { 2 - 7 } & 3.0 & 309.0 & 10.15 & 293.3 & 11.93 & 279.3 & 17.47 \\
\hline
\end{tabular}


Fig. 5 shows the variation of the particle and furnace temperatures at the ignition point, as well as the particle temperature at the massive pyrolysis point with volatile content for the samples weighing 2.0, 2.5, and 3.0 grams. The results show that the particle ignition temperature is 317,324 , and $330^{\circ} \mathrm{C}$ for rice straw, peanut shell, and rice hull respectively. Also, the results indicate that the particle ignition temperature decreases with an increase of volatile content generally. The results of this study agree with the results in the literature $[10,12,15]$. If a larger amount of samples is considered a larger sample particle, then a batch of particles packing together will act as a larger particle with larger pore size. Based on the assumption above, a larger amount of samples should have lower heat loss since its surface/volume ratio is lower; therefore, the ignition temperature of the larger amount of samples should be lower. However, the experimental results with a larger amount of sample show higher ignition temperature by the comparison in Fig. 5. The result is contrary to lower ignition temperature for larger particles. The reason for this finding might be that the interactive influence between particles for a larger amount of samples can retard the heat transfer to the particles inside [4]. Thus, the time required for volatile release will be longer for the larger amount of samples. Therefore, the particle temperature will be higher as oxygen can diffuse to the particle surface to react with residual char as the volatile release is completed.

In general, a material with a lower ignition temperature is easier to ignite. The results indicate that rice straw should be the easiest material to ignite. However, by comparison of the Fz value among experimental samples, the Fz value of rice straw is the lowest $(\mathrm{Fz}=6.28)$, which means that rice straw has the worst ignition characteristics among these three agricultural residues. Therefore, the Fz value might not be suitable to distinguish the ignition characteristics of very high volatile material since the material of $\mathrm{Fz}>2.0$ is categorized as "very easy to burn" [26].

Eq. (7) is used to evaluate the activation energy of the sample particles by the measurement of the particle and furnace temperatures at ignition occurrence, assuming that the particle diameter is in the range of 10-30 mm. The results (in Table 3) indicate that the effect of particle diameter on the calculated activation energy is not significant. Therefore, the uncertainty of particle diameter should not affect the evaluation of the activation energy. However, the effect of sample amounts on the activation energy is significant; hence, it might not be appropriate to consider a larger amount of samples as a larger particle. The interpretation can be used to justify the results showing that the ignition temperature increases with an increase of sample amounts. Nevertheless, since each agricultural residue should have a certain value of activation energy, three levels of sample amounts should be used together to evaluate the activation energy for different samples.

The results show that the average activation energy for rice straw, peanut shell, and rice hull is $157.2,170.3$, and 192.8 $\mathrm{kJ} /$ mole respectively. The calculated activation energy value of the agricultural residues is in the same order as that of the cellulosic material [27-28]. The meaning of lower activation energy indicates that a higher rate of heat generation results in lower ignition temperature. Hence, the evaluation results of activation energy from the Semenov model, which imply the trend of ignition characteristics, are in agreement with the experimental trend.

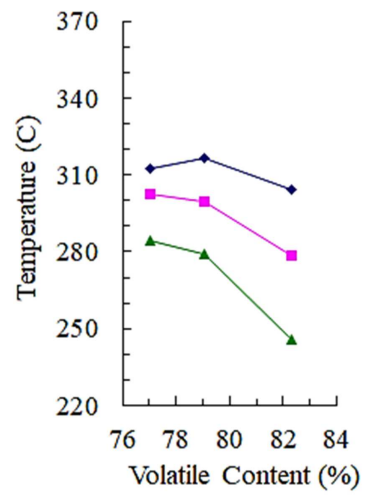

(a) 2.0-gram sample

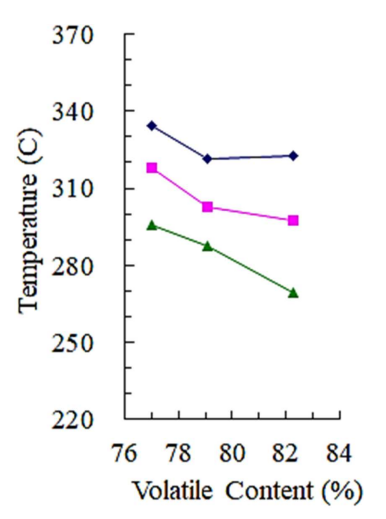

(b) 2.5-gram sample

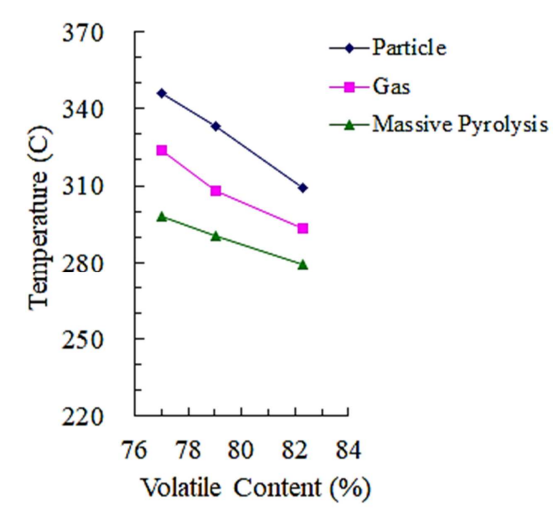

(c) 3.0-gram sample

Fig. 5 Variation of the particle and gas temperatures at the ignition point as well as the particle temperature at the massive pyrolysis point with volatile content 
Table 3 Evaluation of activation energy of agricultural residues by using Eq. (7) and values in literature

\begin{tabular}{|c|c|c|c|c|c|c|}
\hline \multirow[b]{2}{*}{ Sample } & \multirow{2}{*}{$\begin{array}{l}\text { Weight } \\
\text { (g) }\end{array}$} & \multicolumn{5}{|c|}{ Activation energy $(\mathrm{kJ} / \mathrm{mole})$} \\
\hline & & $\mathrm{d}_{\mathrm{p}}=10 \mathrm{~mm}$ & $\mathrm{~d}_{\mathrm{p}}=20 \mathrm{~mm}$ & $\mathrm{~d}_{\mathrm{p}}=30 \mathrm{~mm}$ & Average & $\begin{array}{l}\text { Standard } \\
\text { deviation }\end{array}$ \\
\hline \multirow{3}{*}{$\begin{array}{c}\text { Peanut } \\
\text { shell }\end{array}$} & 2.0 & 192.6 & 193.3 & 193.5 & \multirow{3}{*}{170.3} & \multirow{3}{*}{19.18} \\
\hline & 2.5 & 168.5 & 169.1 & 169.4 & & \\
\hline & 3.0 & 148.4 & 149.0 & 149.3 & & \\
\hline \multirow{3}{*}{$\begin{array}{l}\text { Rice } \\
\text { hull }\end{array}$} & 2.0 & 214.5 & 215.1 & 215.3 & \multirow{3}{*}{192.8} & \multirow{3}{*}{20.86} \\
\hline & 2.5 & 195.8 & 196.4 & 196.6 & & \\
\hline & 3.0 & 166.7 & 167.3 & 167.5 & & \\
\hline \multirow{3}{*}{$\begin{array}{l}\text { Rice } \\
\text { straw }\end{array}$} & 2.0 & 125.1 & 125.7 & 125.9 & \multirow{3}{*}{157.2} & \multirow{3}{*}{34.88} \\
\hline & 2.5 & 143.1 & 143.7 & 144.0 & & \\
\hline & 3.0 & 202.1 & 202.7 & 202.9 & & \\
\hline $\begin{array}{l}\text { Agricultural } \\
\text { residues [27] }\end{array}$ & - & - & - & - & $170-185$ & - \\
\hline $\begin{array}{c}\text { Douglas fir } \\
\text { bark [28] }\end{array}$ & - & - & - & - & $162.8-201.8$ & - \\
\hline
\end{tabular}

\section{Conclusions}

The ignition characteristics of three agricultural residues (peanut shell, rice hull, and rice straw) during the heating process were analyzed by measuring the particle temperature and particle luminosity as well as the gas temperature inside a furnace. No initial flash of light was observed, and the variation rate of particle temperature was fluctuated fiercely by the second derivative of particle temperature with respect to time from the heating curve. Hence, the ignition occurrence was determined by the maximal slope of the particle temperature versus furnace temperature.

The results showed that the particle ignition temperature was 317,324 , and $330^{\circ} \mathrm{C}$ for rice straw, peanut shell, and rice hull, respectively. Also, the results indicated that the particle ignition temperature reduced as the volatile content increased and the sample amount decreased. The value of activation energy, which were analyzed by the Semenov model with the measured ignition temperature, was $152.7,170.3$, and $192.8 \mathrm{~kJ} / \mathrm{mole}$ for rice straw, peanut shell, and rice hull, respectively. The order of decomposition tendency during combustion from the strongest to the weakest was rice straw, peanut shell, and rice hull by the results of ignition characteristics, which was in agreement with the experimental trend.

\section{Nomenclature}

\begin{tabular}{|c|c|c|c|}
\hline $\mathrm{d}_{\mathrm{p}}$ & Particle diameter $(\mathrm{m})$ & $\mathrm{Q}_{\mathrm{l}}$ & Heat loss flux $\left(\mathrm{W} / \mathrm{m}^{2}\right)$ \\
\hline $\mathrm{E}$ & Activation energy $(\mathrm{kJ} / \mathrm{mole})$ & $\mathrm{R}$ & Universal gas constant $(\mathrm{kJ} / \mathrm{mole} . \mathrm{K})$ \\
\hline $\mathrm{FC}$ & Fixed carbon & $\mathrm{T}_{\mathrm{p}}$ & Particle temperature $(\mathrm{K})$ \\
\hline $\mathrm{h}$ & Convective heat transfer coefficient $\left(\mathrm{W} / \mathrm{m}^{2} \cdot \mathrm{K}\right)$ & $\mathrm{T}_{\mathrm{pi}}$ & Particle temperature at ignition $(\mathrm{K})$ \\
\hline $\mathrm{h}_{\mathrm{c}}$ & Heat of combustion $(\mathrm{kJ} / \mathrm{kg})$ & $\mathrm{T}_{\mathrm{g}}$ & Furnace temperature $(\mathrm{K})$ \\
\hline $\mathrm{k}_{\mathrm{o}}$ & Preexponential factor & $\mathrm{T}_{\mathrm{gi}}$ & Furnace temperature at ignition $(\mathrm{K})$ \\
\hline $\mathrm{MC}$ & Moisture content & $\mathrm{VM}$ & Volatile matter \\
\hline $\mathrm{n}$ & Reaction order with respect to oxygen & $\lambda$ & Thermal conductivity of air $(\mathrm{W} / \mathrm{m} . \mathrm{K})$ \\
\hline $\mathrm{p}_{\mathrm{o}}$ & Oxygen concentration & $\sigma$ & Stefan-Boltzmann constant $\left(\mathrm{W} / \mathrm{m}^{2} . \mathrm{K}^{4}\right)$ \\
\hline $\mathrm{Q}_{\mathrm{g}}$ & Heat generation flux $\left(\mathrm{W} / \mathrm{m}^{2}\right)$ & $\varepsilon$ & Emissivity of particle \\
\hline
\end{tabular}

\section{Conflicts of Interest}

The author declares no conflict of interest. 


\section{References}

[1] D. Magalhães, F. Kazanç, A. Ferreira, M. Rabaçal, and M. Costa, "Ignition Behavior of Turkish Biomass and Lignite Fuels at Low and High Heating Rates,” Fuel, vol. 207, pp. 154-164, November 2017.

[2] J. L. Lin, H. M. Keener, and R. H. Essenhigh, "Pyrolysis and Combustion of Corncobs in a Fluidized Bed: Measurement and Analysis of Behavior," Combustion and Flame, vol. 100, pp. 271-282, 1995.

[3] J. B. Howard and R. H. Essenhigh, "Mechanism of Solid-Particle Combustion with Simultaneous Gas-Phase Volatile Combustion," Symp. International on Combustion, vol. 11, no. 1, pp. 399-408, 1967.

[4] R. H. Essenhigh, M. K. Misra, and D. W. Shaw, "Ignition of Coal Particles: A Review," Combustion and Flame, vol. 77, no. 1, pp. 3-30, July 1989.

[5] J. L. Lin, C. S. Lee, and C. T. Sheng, "Measurement and Analysis of Ignition Behavior for Peanut Shell during Combustion," Journal of Agricultural Machinery, vol. 7, no. 3, pp. 61-74, September 1998.

[6] J. M. Jones, A. Saddawi, B. Dooley, E. J. S. Mitchell, J. Werner, D. J. Waldron, et al., "Low Temperature Ignition of Biomass," Fuel Processing Technology, vol. 134, pp. 372-377, June 2015.

[7] H. Fatehi, W. Weng, M. Costa, Z. Li, M. Rabaçal, M. Aldén, et al., "Numerical Simulation of Ignition Mode and Ignition Delay Time of Pulverized Biomass Particles," Combustion and Flame, vol. 206, pp. 400-410, August 2019.

[8] F. Shan, Q. Lin, K. Zhou, Y. Wu, W. Fu, P. Zhang, et al., “An Experimental Study of Ignition and Combustion of Single Biomass Pellets in Air and Oxy-Fuel,” Fuel, vol. 188, pp. 277-284, January 2017.

[9] P. E. Mason, L. I. Darvell, J. M. Jones, M. Pourkashanian, and A. Williams, "Single Particle Flame-Combustion Studies on Solid Biomass Fuels," Fuel, vol. 151, pp. 21-30, July 2015.

[10] H. J. Mühlen and F. Sowa, "Factors Influencing the Ignition of Coal Particles: Studies with a Pressurized Heated-Grid Apparatus," Fuel, vol. 74, no. 11, pp. 1551-1554, 1995.

[11] J. Pedro, S. Seixas, and R. H. Essenhigh, "Ignition Temperature of a High-Ash Portuguese Anthracite: Comparison with a Low-Ash Pennsylvania Anthracite," Combustion and Flame, vol. 66, no. 2, pp. 215-218, November 1986.

[12] T. F. Wall, R. P. Gupta, V. S. Gururajan, and D. K. Zhang, “The Ignition of Coal Particles,” Fuel, vol. 70, no. 9, pp. 1011-1016, September 1991.

[13] Z. Zhang, M. Zhu, J. Li, K. Zhang, G. Xu, and D. Zhang, "Experimental Study of Ignition and Combustion Characteristics of Single Particles of Zhundong Lignite,” Energy and Fuels. vol. 32, no. 4, pp. 4221-4226, 2018.

[14] C. O. Gomez and F. J. Vastola, "Ignition and Combustion of Single Coal and Char Particles: A Quantitative Differential Approach," Fuel, vol. 64, no. 4, pp. 558-563, 1985.

[15] R. P. Gupta, V. S. Gururajan, J. A. Lucas, and T. F. Wall, "Ignition Temperature of Pulverized Coal Particles: Experimental Techniques and Coal-Related Influences," Combustion and Flame, vol. 79, no. 3-4, pp. 333-339, March 1990.

[16] H. Karcz, W. Kordylewski, and W. Rybak. "Evaluation of Kinetic Parameters of Coal Ignition," Fuel, vol. 59, no. 11, pp. 799-802, 1980.

[17] P. G. Sweeny and D. T. Grow, "Ignition and Combustion Characteristics of a Lignite," Energy and Fuels, vol. 3, no. 6, pp. 678-685, 1989.

[18] Y. Zhou, X. Jin, and W. Chu, "Quantitative Measurement and Indication of Pulverized Coal Ignition Temperatures in $\mathrm{O}_{2} / \mathrm{CO}_{2}$ Environments," Applied Thermal Engineering, vol. 112, pp. 888-894, 2017.

[19] W. B. Fu, Y. Ge, M. H. Tang, and T. F. Liu, “A Study on Ignition Criterion of a Large Carbon/Char Particle," Combustion Science and Technology, vol. 108, no. 1-3, pp. 91-101, 1995.

[20] C. L. Sun and M. Y. Zhang, "Ignition of Coal Particles at High Pressure in a Thermogravimetric Analyzer," Combustion and Flame, vol. 115, no. 1-2, pp. 267-274, 1998.

[21] W. B. Fu and T. F. Zeng, "A General Method for Determining Chemical Kinetics Parameters during Ignition of Coal Char Particles," Combustion and Flame, vol. 88, no. 3-4, pp. 413-424, 1992.

[22] S. Ünal, S. Pişkin, and S. Dinçer, “Autoignition Tendencies of Some Turkish Lignites,” Fuel, vol. 72, no. 9, pp. 1357-1359, 1993.

[23] Q. M. Brewster, Thermal Radiative Transfer and Properties, New York: John Wiley \& Sons, 1992.

[24] A. B. Fuertes, E. Hampartsoumian, and A. Williams, "Direct Measurement of Ignition Temperatures of Pulverized Coal Particles," Fuel, vol. 72, no. 9, pp. 1287-1291, September 1993.

[25] P. Ghetti, L. Ricca, and L. Angelini, “Thermal Analysis of Biomass and Corresponding Pyrolysis Products," Fuel, vol. 75, no. 5, pp. 565-573, April 1996.

[26] W. B. Fu and E. Z. Zhang, "A Universal Correlation between the Heterogeneous Ignition Temperatures of Coal Char and Coals," Combustion and Flame, vol. 90, no. 2, pp. 103-113, 1992.

[27] T. Sonobe and N. Worasuwannarak, "Kinetic Analyses of Biomass Pyrolysis Using the Distributed Activation Energy Model," Fuel, vol. 87, no. 3, pp. 414-421, March 2008.

[28] D. Q. Tran and C. Rai, “A Kinetic Model for Pyrolysis of Douglas Fir Bark,” Fuel, vol. 57, no. 5, pp. $293-298$, May 1978.

Copyright $\odot$ by the authors. Licensee TAETI, Taiwan. This article is an open access article distributed under the terms and conditions of the Creative Commons Attribution (CC BY-NC) license

(https://creativecommons.org/licenses/by-nc/4.0/). 